\title{
Development of sandwich panels combining fibre reinforced concrete layers and fibre reinforced polymer connectors. Part II: Evaluation of mechanical behaviour
}

\author{
Rodrigo Lameiras*, Joaquim Barros, Miguel Azenha, Isabel B. Valente \\ ISISE - Institute for Sustainability and Innovation in Structural Engineering, University of Minho, School of Engineering, Department of Civil Engineering, Campus de Azurém, 4800-058 \\ Guimarães, Portugal
}

\section{A R T I C L E I N F O}

\section{Article history:}

Available online 22 June 2013

\section{Keywords:}

Insulated panels

Load-bearing panels

Sandwich panels

Steel fibre reinforced self-compacting

concrete (SFRSCC)

Glass fibre reinforced polymer (GFRP)

Finite Element (FE) simulation

\begin{abstract}
A B S T R A C T
In the first part of this paper the authors describe an innovative sandwich panel that comprises Glass Fibre Reinforced Polymer (GFRP) connectors and two thin layers of Steel Fibre Reinforced Self-Compacting Concrete (SFRSCC). This second part of the paper reports the investigation performed by the authors based on the numerical simulation of these sandwich panels. The simulations use the Finite Element Method (FEM) software implemented by the second author (FEMIX). Through linear static analyses and consideration of Ultimate Limit State loading scenarios, parametric studies were performed in order to optimise the arrangement of the GFRP connectors and the thickness of the SFRSCC layers. Moreover, models considering a specific nonlinear behaviour of SFRSCC were also constructed in order to simulate the progressive damage of the panel induced by cracking. In the scope of the nonlinear analyses, emphasis is given to parameter estimation of fracture modelling parameters for the fibre reinforced concrete based on both inverse analysis and the fib Model Code.
\end{abstract}

(c) 2013 Elsevier Ltd. All rights reserved.

\section{Introduction}

In the first part of this paper [1] the authors proposed an innovative insulated panel to be used as a load-bearing wall of modular buildings. This panel comprises Glass Fibre Reinforced Polymer (GFRP) connectors and two thin outer layers of Steel Fibre Reinforced Self-Compacting Concrete (SFRSCC). Although different types of FRP connectors have been already investigated for reinforced/prestressed concrete sandwich panels [2-6] and the SFRSCC was suggested as the material for sandwich panels [7], the combination of FRP and SFRSCC to obtain a sandwich panel that takes advantage of both materials is unknown at present phase.

Besides the use of unconventional materials, the proposed construction system has other peculiarities that turn it attractive. The walls act as the primary load carrying components of the structure transferring the loads to the foundation of the structure. The single storey wall panels span vertically between foundations and floor/ roof panels without the need for additional intermediate supports. For aesthetic and practicality reasons, the vertical load is applied only in the inner SFRSCC wythe. In this context, the GFRP laminar connectors proposed and evaluated experimentally by the authors

\footnotetext{
* Corresponding author. Tel.: +351 253510 200; fax: +351 253510217 .

E-mail address: rmlameiras@civil.uminho.pt (R. Lameiras).
}

in the first section plays an important role in the structural system to make the two layers of SFRSCC act jointly to withstand the actions to which the structural panels are exposed.

This paper arises thereby from the need for a better understanding of the structural behaviour of the proposed system. Efforts are made for assessing the best solutions for the geometry of the panel components and arrangement of GFRP connectors, through parametric analyses. The studies include analyses of the panel subjected to the combined action of axial loadings (i.e.: slab's reaction) and wind load pressure. The forces due to seismic action were disregarded, since the dwellings have been initially designed for non-seismic areas. In the parametric studies, the proposed wall system is analysed at the Ultimate Limit State (ULS) using linear Finite Element (FE) analysis procedures. Through these analyses the geometry and arrangement of the panel components are designed to resist the imposed loadings in the elastic range with no or minor damage. For a better understanding of how the proposed solution for the structural system performs when subjected to extreme loading conditions such as high winds, a nonlinear design of the sandwich panels is also performed taking into account the degradation (i.e.: cracking) of the SFRSCC layers. Through the nonlinear analyses, the ductility of the proposed system under severe conditions is verified, providing the evolution of inelastic phenomena such as crack widths and deflections.

Although the FE numerical modelling of the mechanical behaviour of sandwich concrete panels have been already presented in 
the literature by other authors [8-10], this work differs from the other researches due to the laminar nature of the GFRP connectors and also due to the particular loading condition that characterises the proposed structural system (i.e.: vertical load applied only to the internal SFRSCC layer). Moreover, due to the specific proposal of using SFRSCC layers without any reinforcing bar, in this paper emphasis is given to the choice of the fracture parameters that characterises the SFRSCC, where two different approaches to model the nonlinear behaviour of the SFRSCC are compared.

\section{Parametric studies for the design of the sandwich panels}

To better understand the structural behaviour of the panel, a set of systematic parametric studies based on linear elastic modelling of the sandwich panels was carried out. At an initial stage, focus was given to the optimum arrangements and properties of the parts of the sandwich panel. The parameters considered in these studies were: the position, orientation and continuity of the GFRP connectors and the thickness of the SFRSCC layers. The FEM-based software FEMIX [11] was used for these analyses. A linear and elastic analysis was adopted for this phase of the design process, since preliminary tests with small size prototype systems of the sandwich panel have indicated that damage due to cracking of SFRSCC had minor relevance even for loading levels corresponding to the ultimate limit state design conditions [12]. This decision was also caused by the relatively high computing time of material nonlinear analysis of real size sandwich panels requiring to find the best configuration for the constituent elements of the panel.

\subsection{Common features: geometry, mesh, loading, support conditions and material properties}

In this work all the analyses were limited to a reference sandwich panel of $8.00 \mathrm{~m}$ length, with an external $\left(h_{\text {ext }}\right)$ and an internal $\left(h_{\text {int }}\right)$ SFRSCC layer of $2.60 \mathrm{~m}$ and $2.40 \mathrm{~m}$ free height, respectively (see Fig. 1 from the first part of this paper [1]). The length of the panel was determined by transportation and handling constraints. In turn, the height of the internal SFRSCC layer was related to the minimum ceiling height of the building. The height of the external SFRSCC layer was defined as the height of the internal layer plus the thickness of the slab or roof that is supported by the internal layer. The thickness of the insulating material was kept equal to $100 \mathrm{~mm}$, whereas the thickness of the SFRSCC layers was one of the variables studied. These dimensions are consistent with the ones of the conventional sandwich panels, according to the PCI Committee on Precast Sandwich Wall Panels [13].

Similar finite element (FE) meshes were adopted for the different panels, differing only on the position of connectors. The FE meshes of the sandwich panels consisted of Reissner-Mindlin flat shell eight nodes finite elements for modelling the internal and external SFRSCC wythes, as well as the GFRP connectors (see Fig. 1). The FE mesh coincides with the middle surface of these components of the sandwich panel. The Gauss-Legendre integration scheme with $2 \times 2$ points was used in all elements. The FE models assumed that bond between materials (SFRSCC and GFRP) is perfect. In the first part of this paper, the pullout responses for different types of connections were presented and a high initial rigidity of these connections was observed. In the authors' opinion, this observed behaviour justifies the possibility of considering perfect bond between both materials during the linear stage.

The contribution of the thermal insulating material for the structural behaviour of the panel is disregarded. In fact, previous experimental research has shown that the contribution to the composite action of sandwich panels provided by the bond between the concrete layers and insulation is less than 5\% [6]. Moreover, due to the movements that the panels are subjected, caused by thermal gradients and/or wind load, the bond between concrete and insulating material cannot be guaranteed along all the service life of the structure.

The panels are subjected to both horizontal ( $x$ direction according to the referential defined in Fig. 1 ) and vertical loads ( $z$ direction). It is considered that the roof/floors transfer the vertical forces to the load-bearing walls and into the foundation through the SFRSCC layer that faces the interior of the building, herein designated as internal layer of the sandwich panel (Fig. 2). The lateral loads (i.e.: wind) are withstood by the sandwich wall panels that span between the floor/roof and the foundation. Floor/roof systems, herein designated as slabs, are considered to act as horizontal diaphragms, in the sense that horizontal loads are carried through these diaphragms into the shear walls (the sandwich wall panels in orthogonal direction to the panel studied herein). These supporting conditions are shown in Fig. 2.

The vertical loads correspond to the self-weight of the wall panel and the load $\left(R_{S L}\right)$ transferred by the slab (10.0 $\mathrm{m}$ of span), which is simulated by a centred line force applied to the upper edge of the internal SFRSCC layer (see the schematic representation in Fig. 2). In order to guarantee this condition in practice the connections between the wall panels and the slabs are designed to

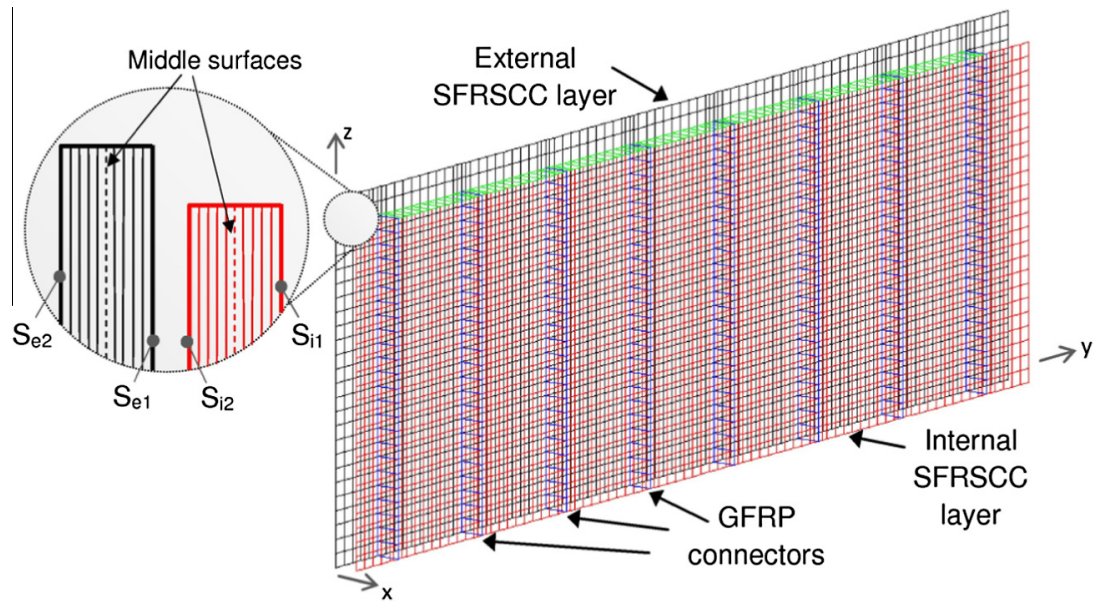

Fig. 1. View of FE mesh adopted for panels consisting of arrangements C, D and E, and detail of the layered shell elements. 
(a)

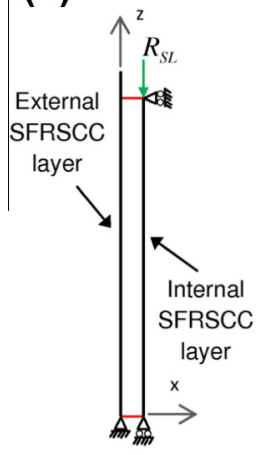

(b)

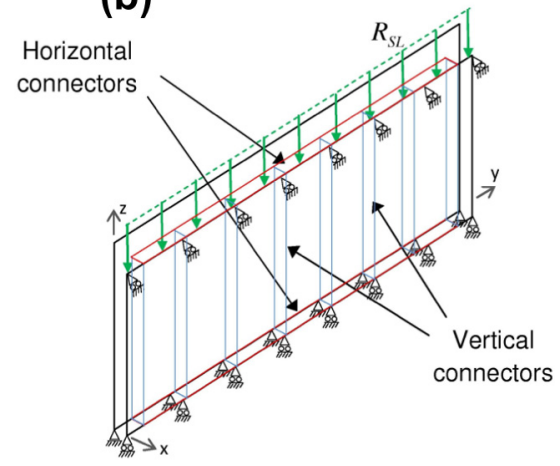

Fig. 2. Schematic representation of support conditions and forces transferred by the slab: (a) cross-section; (b) perspective view.

transmit only the vertical load centred in the internal SFRSCC layer, not transmitting moments (e.g.: simply supported slabs over neoprene strips installed centred in the top surface of the internal SFRSCC layer).

The wind loading is computed following the simplified procedure described in the Eurocode 1 - Part 1-4 [14], with consideration of an open building situation. In consequence, the wind load acts as a uniform pressure, directly towards the surface, or suctions, directly away from the surface, on the external and internal surfaces of the panel. The values that lead to the most unfavourable conditions considered in the Portuguese National Annex are chosen. The described load cases are included in three different relevant Ultimate Limit States (ULS) combinations: LC1 - external SFRSCC layer under pressure and internal SFRSCC layer under suction; LC2 - external SFRSCC layer under suction and internal SFRSCC layer under pressure; and LC3 - both layers under suction (see Fig. 3, Tables 1 and 2). These load cases and values are defined depending on the aspect ratio of building and on the size and distribution of the openings in the building envelope. The values indicated in Tables 1 and 2 are defined in the $x, y, z$ Global Coordinate System (GCS), so a negative value means that the direction of the applied force is opposite to the corresponding axis of the GCS.

The SFRSCC and GFRP properties used in the panel simulations are the ones experimentally determined and presented in the first part of the paper [1]. The SFRSCC was characterised by a modulus of elasticity of $35.45 \mathrm{GPa}$. The GFRP was characterised by a modulus of elasticity of $12.65 \mathrm{GPa}$. The Poisson's ratios considered were

Table 1

Adopted values for the load cases.

\begin{tabular}{lll}
\hline Load cases & & \\
\hline Gravity load & $G$ & - \\
Slab reaction (design value) & $R_{S L}$ & $-48.75 \mathrm{~N} / \mathrm{mm}$ \\
LC1 - external wind force & $W_{E X 1}$ & $+1.021 \mathrm{e}-03 \mathrm{~N} / \mathrm{mm}^{2}$ \\
LC1 - internal wind force & $W_{I N 1}$ & $+6.381 \mathrm{e}-04 \mathrm{~N} / \mathrm{mm}^{2}$ \\
LC2 - external wind force & $W_{E X 2}$ & $-1.531 \mathrm{e}-03 \mathrm{~N} / \mathrm{mm}^{2}$ \\
LC2 - internal wind force & $W_{I N 2}$ & $-4.466 \mathrm{e}-04 \mathrm{~N} / \mathrm{mm}^{2}$ \\
LC3 - external wind force & $W_{E X 3}$ & $-1.531 \mathrm{e}-03 \mathrm{~N} / \mathrm{mm}^{2}$ \\
LC3 - internal wind force & $W_{I N 3}$ & $+6.381 \mathrm{e}-04 \mathrm{~N} / \mathrm{mm}^{2}$ \\
\hline
\end{tabular}

Table 2

Load combinations.

\begin{tabular}{ll}
\hline Load combinations (ULS) & \\
\hline LC1 & $1.35 G+1.0 R_{S L}+1.5\left(W_{E X 1}+W_{I N 1}\right)$ \\
LC2 & $1.35 G+1.0 R_{S L}+1.5\left(W_{E X 2}+W_{I N 2}\right)$ \\
LC3 & $1.35 G+1.0 R_{S L}+1.5\left(W_{E X 3}+W_{I N 3}\right)$ \\
\hline
\end{tabular}

0.15 and 0.40 , respectively for the concrete and GFRP. Moreover, both materials were simulated assuming a linear and isotropic behaviour.

The thickness of the GFRP flat shell connectors was held constant with $2.5 \mathrm{~mm}$. This is the same thickness adopted in the connectors used in the experimental program presented in the first part of the paper [1].

\subsection{Effect of the arrangement of the connectors on the maximum stresses and transversal displacements of the panel}

In a first stage, the effect of the arrangement adopted for the connectors of the sandwich panels on the maximum tensile principal stresses and on the deformability of the proposed panel was studied in order to determine the most effective arrangements. In this study, the thickness of the SFRSCC flat layers was kept constant and equal to $75 \mathrm{~mm}$. This thickness was chosen because it is a typical value for sandwich panels comprising conventionally reinforced concrete layers [13].

Both vertical and horizontal connectors were considered. The use of continuous and discrete connectors was explored. The arrangements studied are described in Fig. 4. Arrangement A consists of three vertical continuous connectors and one horizontal connector. The vertical connectors are spaced $3.50 \mathrm{~m}$ from each
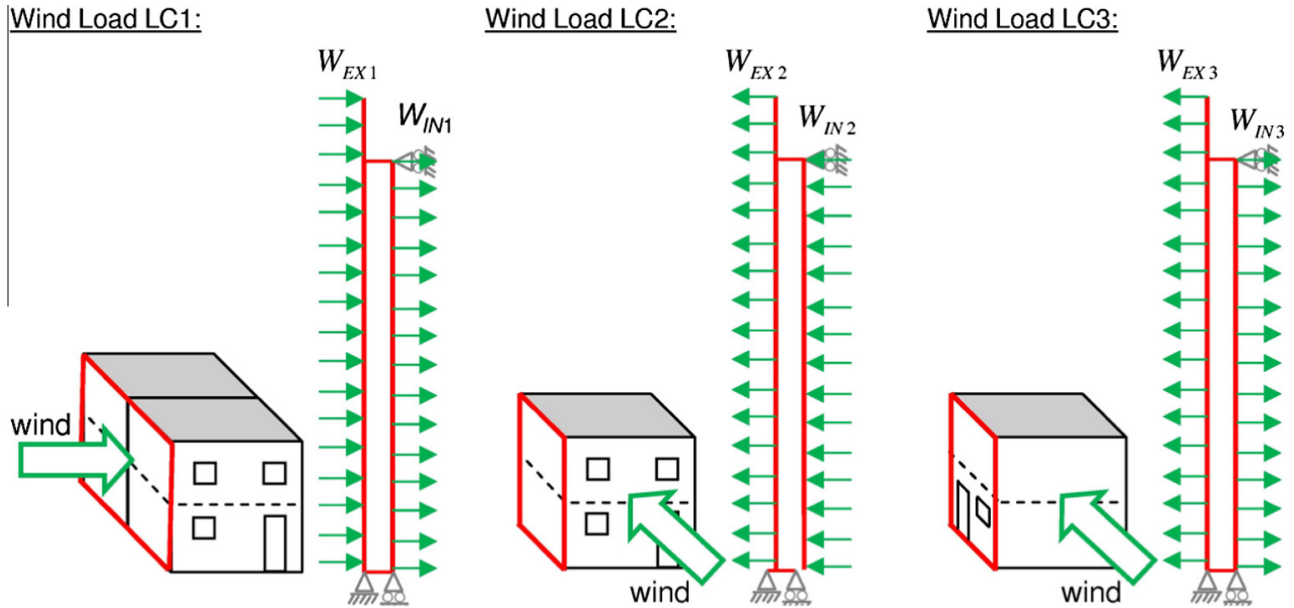

Fig. 3. Wind load cases 


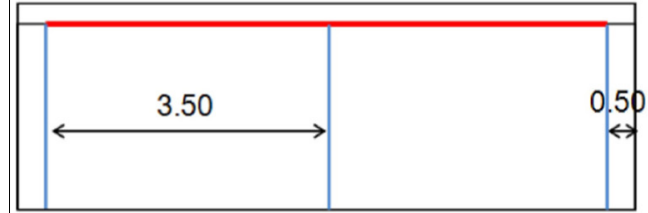

(a) Arrangement $A$

GFRP Vertical: continuous, spaced $3.50 \mathrm{~m}$

GFRP Horizontal: continuous, along the upper edge Total length of connectors: $14.20 \mathrm{~m}$

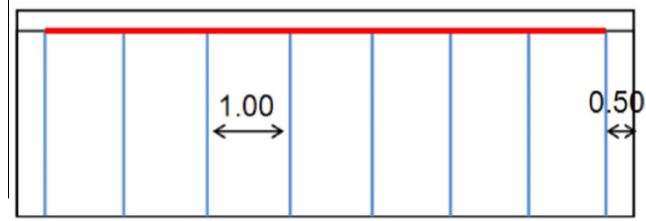

(c) Arrangement $\mathrm{C}$

GFRP Vertical: continuous, spaced $1.00 \mathrm{~m}$ GFRPH: continuous, along the upper edge Total length of connectors: $26.20 \mathrm{~m}$

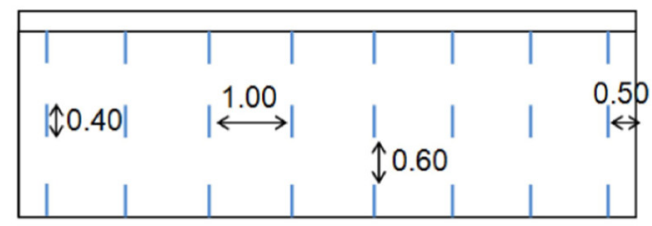

(e) Arrangement $\mathrm{E}$

GFRP Vertical: discrete, spaced horizontally $1.00 \mathrm{~m}$ and vertically $0.60 \mathrm{~m}$ from each other

GFRP Horizontal: none

Total length of connectors: $9.60 \mathrm{~m}$

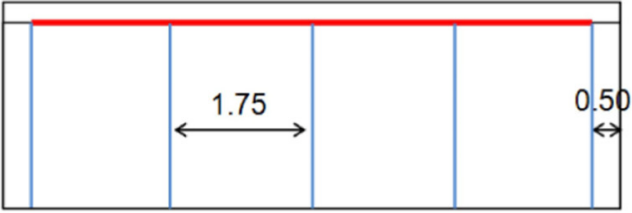

(b) Arrangement B

GFRP Vertical: continuous, spaced $1.75 \mathrm{~m}$

GFRP Horizontal: continuous, along the upper edge Total length of connectors: $19.00 \mathrm{~m}$

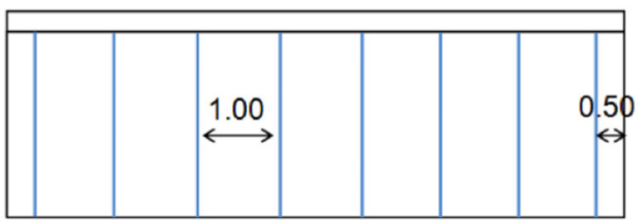

(d) Arrangement $D$

GFRP Vertical: continuous, spaced $1.00 \mathrm{~m}$

GFRPH: none

Total length of connectors: $19.20 \mathrm{~m}$

Fig. 4. Arrangements of connectors studied: (a) A; (b) B; (c) C; (d) D and (e) E (units in metres).

other. In arrangements B and C, the distance between vertical connectors are, respectively, $1.75 \mathrm{~m}$ and $1.00 \mathrm{~m}$. Arrangement $\mathrm{D}$ is similar to arrangement $\mathrm{C}$ but without the horizontal connector. Arrangement E consists of eight vertical lines of three discrete connectors each, spaced horizontally $1.00 \mathrm{~m}$ from each other as in arrangement D. These discrete connectors are $0.40 \mathrm{~m}$ long each, regularly distributed along the height of internal concrete layer and vertically spaced of $0.60 \mathrm{~m}$. Since the total cost of the panel is influenced by the number and length of connectors employed, it is important to stress that the different arrangements influence the total length of connectors (Fig. 4).

It may be considered that the panel is casted in the horizontal position (see Fig. 3 from the first part of the paper [1]) and that the panel is stripped by the internal SFRSCC layer. Then, the load corresponding to the weight of the external SFRSCC layer is transferred to the internal SFRSCC layer through the GFRP connectors. For SFRSCC layers of $75 \mathrm{~mm}$, assuming that the unit weight of SFRSCC is $25 \mathrm{kN} / \mathrm{m}^{3}$ and that a total volume of $8.00 \times 2.65 \times 0.075 \mathrm{~m}^{3}\left(1.59 \mathrm{~m}^{3}\right)$ is lifted, a total weight of $39.75 \mathrm{kN}$ should be withstood by the connections. Moreover, if a suction/adhesion of $3 \mathrm{kN} / \mathrm{m}^{2}$ is assumed to be imposed by mould during demoulding process [15], and considering the area of contact between the external SFRSCC layer and the mould of $8.00 \times 2.65 \mathrm{~m}^{2}\left(21.2 \mathrm{~m}^{2}\right)$, a value of $63.6 \mathrm{kN}$ should be added to the weight of the unit. So, a total of $103.35 \mathrm{kN}$ must be supported by the connections. Considering the arrangement with the minimum length of connector (arrangement $\mathrm{E}$, with $9.6 \mathrm{~m}$ ), the total applied load per unit length is equal to $10.76 \mathrm{kN} / \mathrm{m}$, which corresponds to $15 \%$ of the average load capacity of adhesively bonded connectors (the connector that presents the lower load capacity between the studied types). The authors are aware of the simplicity of the assumption that the stresses on the connectors are uniform during demolding, which probably does not occur in practice. However, as the stress level is much lower than the tensile strength of the connectors, it is expectable that even for more complex lifting configurations the strength of the GFRP is not attained.

Fig. 5 shows the evolution of the maximum principal tensile stress $\left(\sigma_{1}\right)$ in both SFRSCC layers and also in the GFRP connectors for the five panel configurations studied. The values presented in these charts correspond to stress envelopes for the load combinations presented in the Section 2.1. From these results, it is possible to infer that a lower spacing between the vertical connectors reduces the stress level in both SFRSCC layers. It may be further noted that the omission of horizontal connectors (arrangement D) does not imply relevant changes in terms of principal stresses in SFRSCC and GFRP. It can be also observed that, independently of the arrangement, the maximum tensile stress in the GFRP connectors is always much lower than the tensile strength of the material, reaching a maximum of $3.6 \%$ of the corresponding ultimate capacity for the arrangement $A$.

Attention should be paid to the fact that the model used for the numerical simulations has limitations. As connections between GFRP and SFRSCC were modelled as perfectly bonded, this modelling approach cannot simulate the failure of the connection itself. Considering this limitation and although the mechanisms occurring in the connection under bending are different from what happens in the pull-out tests, it is possible to perform a partial evaluation on the integrity of the connections, by comparing the principal tensile stresses obtained through the numerical 
(a)
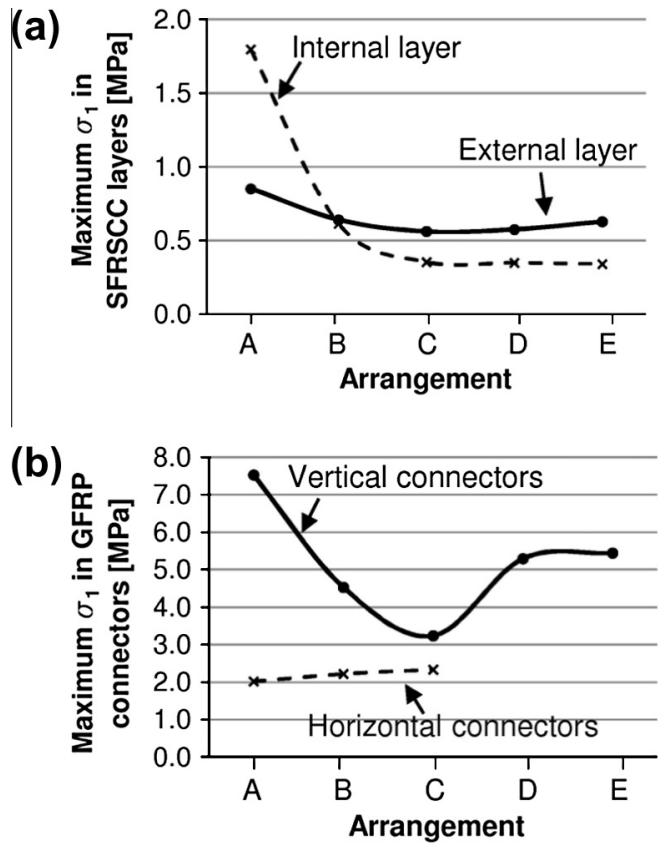

Fig. 5. Influence of connector arrangement on the maximum principal stresses $\left(\sigma_{1}\right)$ of: (a) SFRSCC layers; (b) GFRP connectors (positive values signify tension)

simulations with the maximum tensile stresses in the free section of the GFRP in the pull-out tests performed in Lameiras et al. [1]. Considering that the CSM laminate is a linear elastic material and that an uniform distribution of stresses is attained in the GFRP section during the pull-out tests, the minimum and maximum tensile stresses in the free section of GFRP corresponding to the connection failure were 18.4 MPa and 58.32 MPa, obtained respectively for the adhesively bonded (TAB) and T-profiled embedded connectors (TEM) (see [1]). On the other hand, in the current parametric study, the maximum tensile stress in the GFRP was 7.27 MPa, obtained for the arrangement A. Thus, even for a sandwich panel comprising adhesively bonded connections with the adhesive spread only in the flanges of the GFRP profiles, it is expected that the connections will be intact when subjected to the load combinations corresponding to the Ultimate Limit States.

For SFRSCC layers of $75 \mathrm{~mm}$, the maximum principal tensile stress does not reach the tensile strength of SFRSCC in any of the studied arrangements. For arrangements B, C, D and E the maximum stress level is similar in both layers, which is a desirable situation, since the material and the thickness adopted for both layers are the same. In addition, the use of discrete connectors does not lead to a significant increase of the maximum principal stresses in the SFRSCC neither in the GFRP. Thus, from these obtained results it can be concluded that the arrangement $\mathrm{E}$, with only discrete vertical connectors with $0.40 \mathrm{~m}$ length, distanced vertically of $0.60 \mathrm{~m}$ and horizontally of $1.00 \mathrm{~m}$ from each other, can be adopted, keeping a low stress level in the SFRSCC layers and GFRP connectors.

The influence of the connectors' arrangement on the maximum transversal displacements of SFRSCC layers ( $x$ direction) is presented in Fig. 6.

The obtained results show that the transversal displacements in the panel are relatively small for all the arrangements studied, even in panels consisting of vertical discrete connectors. Moreover, the results show that for the arrangements B, C, D and E, the maximum transversal displacements are similar for both concrete layers, which does not happen for the arrangement A. For this reason, and considering that panels with the arrangement E use exactly

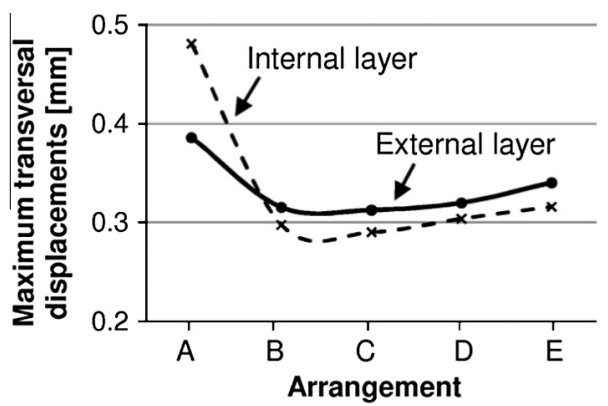

Fig. 6. Influence of connector arrangement on the maximum transversal displacement in the panel.

half total length of connectors used in arrangement D, the arrangement $\mathrm{E}$ was chosen as the most attractive solution to be adopted in the following studies.

2.3. Effect of the thickness of SFRSCC layers on the maximum stresses and transversal displacements in the panel

From the economic point of view, it is advantageous to design the sandwich panels by minimising the consumption of raw materials. Since the SFRSCC is a material with relatively high impact in the global costs of the building, the thickness of the concrete layers should be reduced as much as possible. In order to assess the possibility of reducing the thickness of the concrete layers, numerical analyses of panels with the connector arrangement E (Fig. 4e) and SFRSCC layers with thickness of 35, 45, 55, 65 and $75 \mathrm{~mm}$ were performed.

The effect of the thickness of SFRSCC layers on the maximum value of the principal tensile stresses in these layers and on the GFRP connectors are depicted in Fig. 7. From the obtained results, it may be observed that even for sandwich panels comprising layers of $35 \mathrm{~mm}$ thickness, the maximum principal tensile stresses are lower than half of the tensile strength of SFRSCC. It is also observed

(a)
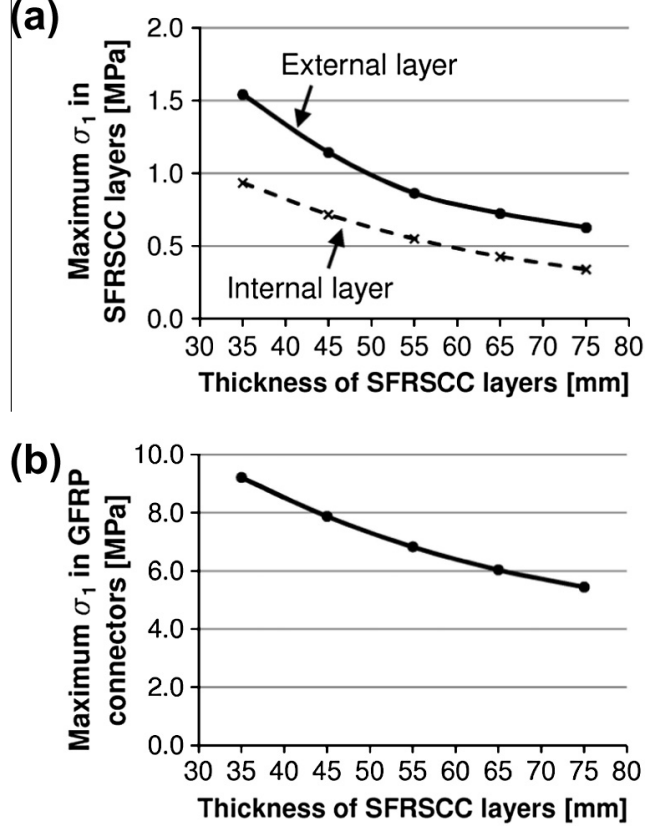

Fig. 7. Influence of thickness of SFRSCC layer on the maximum principal stresses $\left(\sigma_{1}\right)$ in: (a) SFRSCC layers; (b) GFRP vertical connectors (positive values signify tension). 


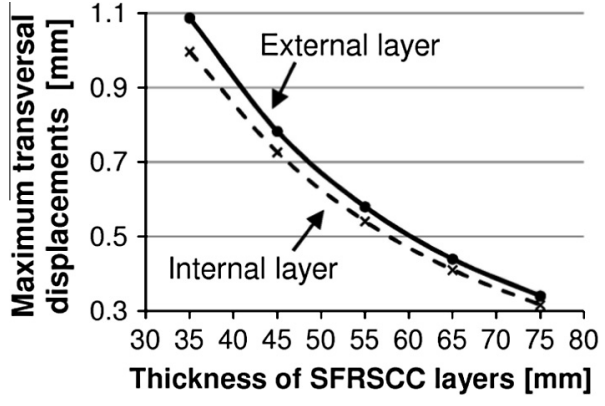

Fig. 8. Influence of the thickness of SFRSCC layers on the maximum transversal displacement in the panel with the arrangement $\mathrm{E}$.

that the reduction of the thickness of SFRSCC layers from $75^{\circ}$ to $35 \mathrm{~mm}$ is accompanied by an increase of the maximum tensile stresses in the connectors from 5.45 to $9.22 \mathrm{MPa}$. These values are not significant when compared to the connector's tensile strength, once they correspond to only $2.6 \%$ and $4.4 \%$ of the ultimate GFRP tensile strength, respectively.

By comparing the maximum principal stresses in the GFRP with the maximum tensile stresses in the free section of GFRP during the pull-out tests (minimum of $18.4 \mathrm{MPa}$ for the TAB connector), it can be concluded that even for a panel comprising layers of $35 \mathrm{~mm}$ thickness and adhesively bonded connectors, all the connections may be intact when the panel is subjected to load combinations corresponding to the ULS.

The influence of the thickness of SFRSCC layers on the maximum transversal displacements is depicted in Fig. 8. These results show that the maximum transversal displacement of the panel increases with the decrease of thickness on the SFRSCC layers. The maximum transversal displacement reaches a maximum of $1.09 \mathrm{~mm}$ in a panel consisting of SFRSCC layers with $35 \mathrm{~mm}$ thickness. The panel spans $2.40 \mathrm{~m}$ between the foundation and the slab and, therefore, this displacement corresponds to $\mathrm{h} / 2200$ for ultimate limit state. This value is much lower than the deflection limit of $\mathrm{h} / 480$ ( $5 \mathrm{~mm}$ ) given in the literature for precast wall panels under service loads [16].

After the results presented in Figs. 7 and 8, it was concluded that the thickness of the concrete wythes could be much less than $75 \mathrm{~mm}$. However, if an effective connection is to be achieved with embedded shear connectors, it is important to ensure a minimum thickness, so that the connector can be positioned inside the concrete layer in order to effectively transfer the stresses between the two SFRSCC layers. In this type of connection there are constructive/technological constraints that also should be taken into account. Considering that is necessary to keep the connectors covered with 15 to $20 \mathrm{~mm}$ (otherwise there is a high risk of forming a crack coinciding with the plane of the GFRP connector due to the difficulty of assuring proper conditions for the distribution of aggregates and fibres in this zone), and that the holes of the perforated plates should be at least 3 times the size of the maximum diameter of the aggregate used in the SFRSCC, it seems that a thickness of $60 \mathrm{~mm}$ is a reasonable value for the SFRSCC flat layers. However, this parametric study shows that if another kind of connection is possible (e.g.: adhesively bonded connections), a panel comprising SFRSCC layers as thin as $35 \mathrm{~mm}$ could meet the structural performance requirements. Another technological solution to materialise the embedded connections could be the use of ribbed SFRSCC layers. With this solution the panels could be thicker only in the vicinity of the connectors, keeping a reduced thickness throughout the current section of the panel.

The in-plane stress fields in the $z$ and $y$ directions in the external SFRSCC layer for a panel with arrangement $E$ and SFRSCC layers of $60 \mathrm{~mm}$ thick, submitted to the load combination LC2 (most critical one) are shown in Fig. 9. It can be observed that the highest stresses are localised at the middle zone of the panel and at the top

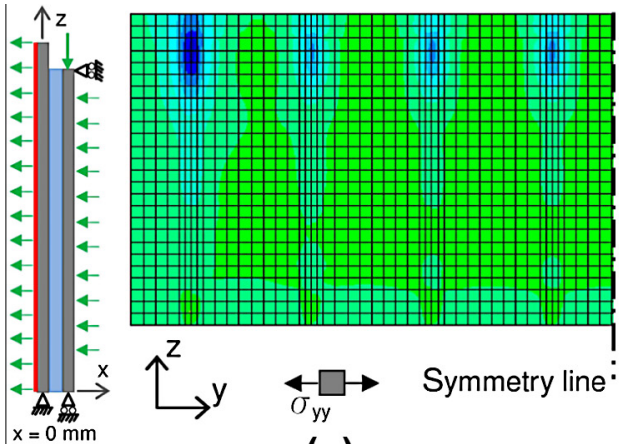

(a)

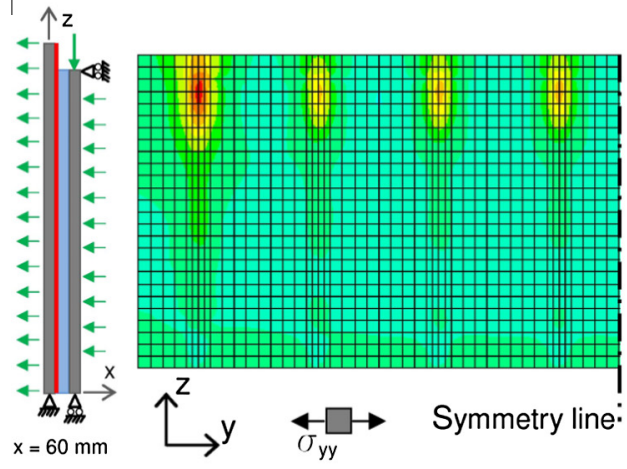

(c)

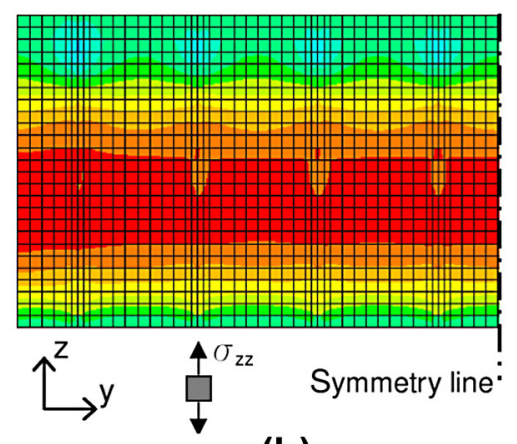

(b)

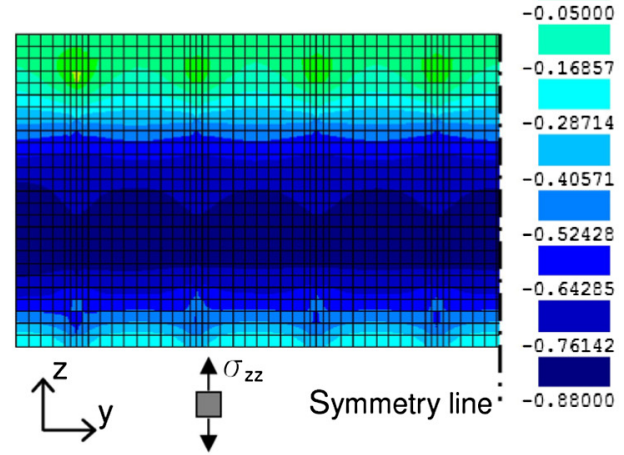

(d)

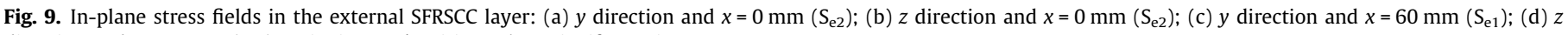
direction and $x=60 \mathrm{~mm}\left(\mathrm{~S}_{\mathrm{e} 1}\right)$. Units in $\mathrm{MPa} /$ positive values signify tension. 
(b)
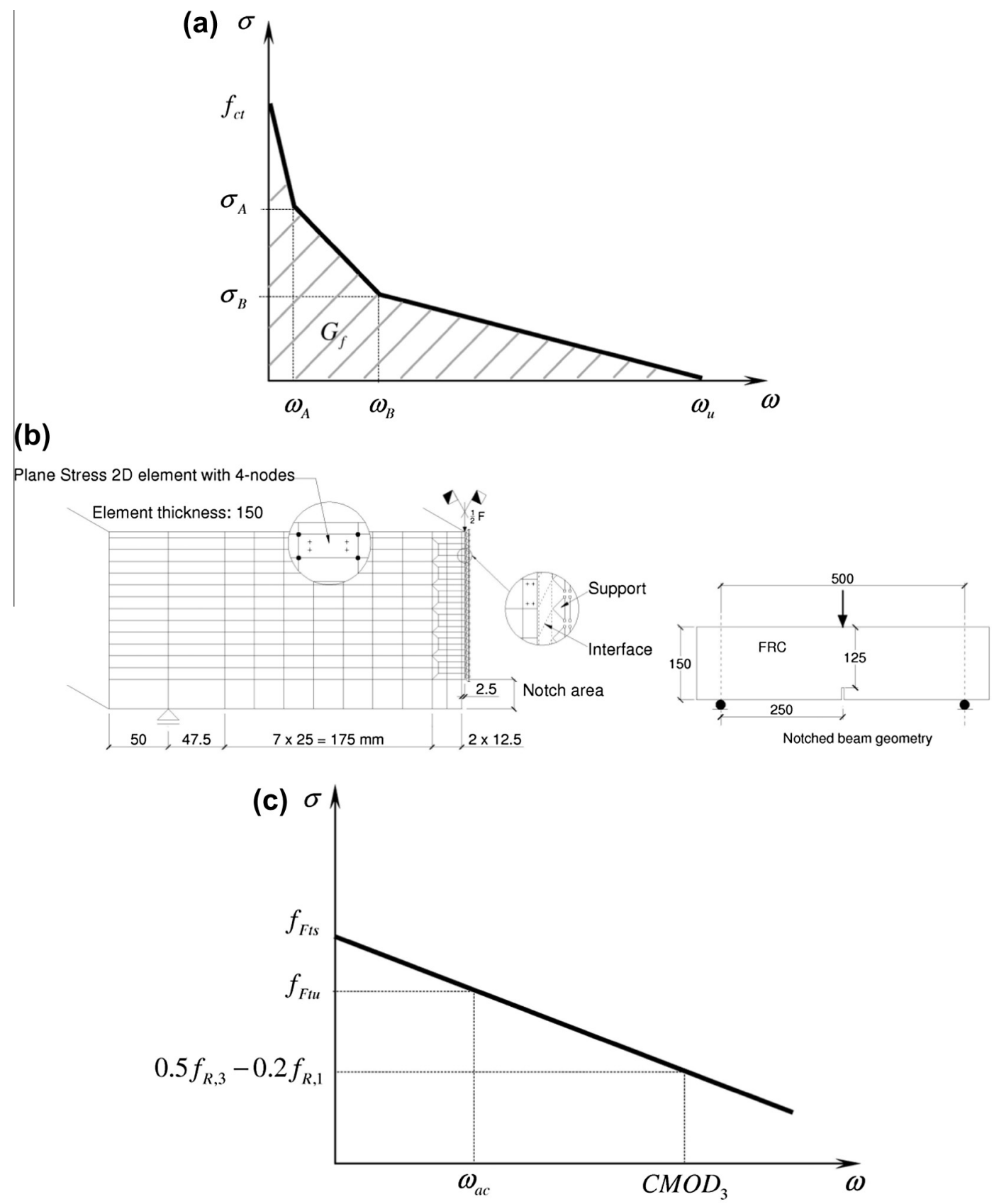

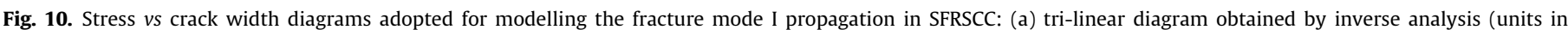
millimetres); (b) finite element mesh adopted in the inverse analysis; (c) linear diagram determined according the recommendations of fib Model Code 2010.

Table 3

Values of the parameters of the tri-linear $\sigma-\omega$ diagram computed by inverse analysis.

\begin{tabular}{|c|c|c|c|c|c|c|c|c|c|}
\hline$f_{c t}(\mathrm{MPa})$ & $\omega_{1}(\mathrm{~mm})$ & $\sigma_{1}(\mathrm{MPa})$ & $\omega_{2}(\mathrm{~mm})$ & $\sigma_{2}(\mathrm{MPa})$ & $\omega_{u}(\mathrm{~mm})$ & $G_{f}(\mathrm{~N} / \mathrm{mm})$ & $\operatorname{err}_{0.5}(\%)$ & $\operatorname{err}_{1.0}(\%)$ & $\operatorname{err}_{2.0}(\%)$ \\
\hline 3.30 & 0.050 & 2.64 & 0.300 & 3.63 & 2.300 & 4.56 & 2.5 & 1.9 & 6.9 \\
\hline
\end{tabular}

extremity of the top connectors, due to the fundamental flexural behaviour of the panel in the $x z$ plane. However, the calculated stress values are much lower than the compressive and tensile strength of the developed SFRSCC.

\section{Material nonlinear analysis}

Despite the linear analyses have indicated that, even for the ultimate limit states, the stress levels attained in the different components of the panels are far below their resistance, it was decided to perform FEM-based material nonlinear analysis in the present section in order to predict the behaviour of the selected sandwich panel configuration up to relatively high damage levels (only probable at extreme loading conditions).

To simulate the material nonlinear behaviour of the panel due to crack initiation and propagation in SFRSCC the version 4.0 of FEMIX computer program [11] was used, since it is capable of 


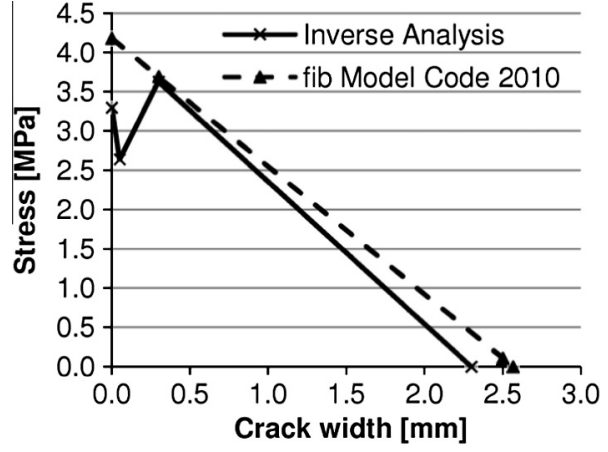

Fig. 11. $\sigma-\omega$ diagrams adopted in the material nonlinear analysis of the panels.
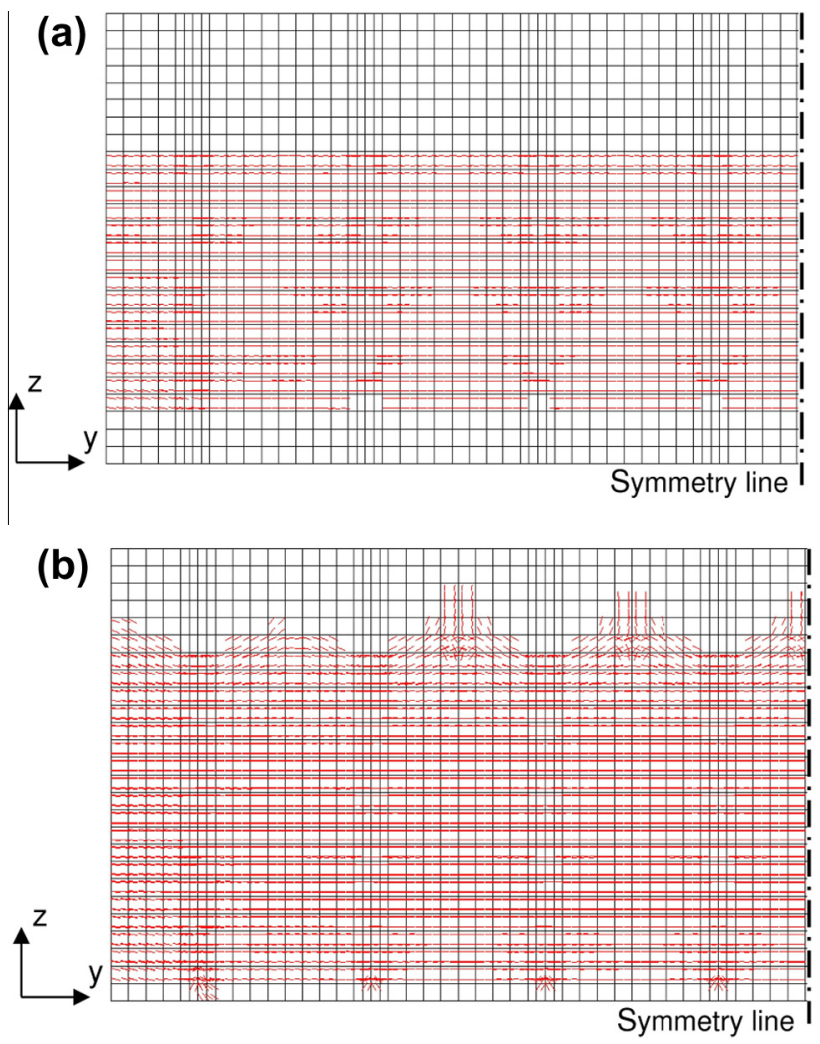

Fig. 12. Crack pattern at the external surface of the external SFRSCC layer $\left(S_{e 2}\right)$ for the load case LC2, and for a load factor corresponding to a maximum crack width of: (a) $0.01 \mathrm{~mm}$ and (b) $0.10 \mathrm{~mm}$.

modelling the post-cracking behaviour of fibre reinforced concrete materials.

The geometry, mesh and support conditions were those of the parametric study described in the previous section. The analyses of the present section pertain to the arrangement $\mathrm{E}$ of connectors, and thickness of SFRSCC layers of $60 \mathrm{~mm}$.

In order to simulate the progressive damage induced by cracking, the concrete shell element thickness was discretized in layers, where each of them was considered in a state of plane stress. The concrete cracking was simulated with a multi-directional fixed smeared crack constitutive model, which is conceptually justified due to the diffuse crack patterns expected to be formed during the loading process of the panel. According to Barros and Figueiras [17], the fracture energy is dissipated over a crack band width, $l_{b}$. In the present simulations, it is assumed a crack band width equal to the square root of the area of the corresponding integration point.
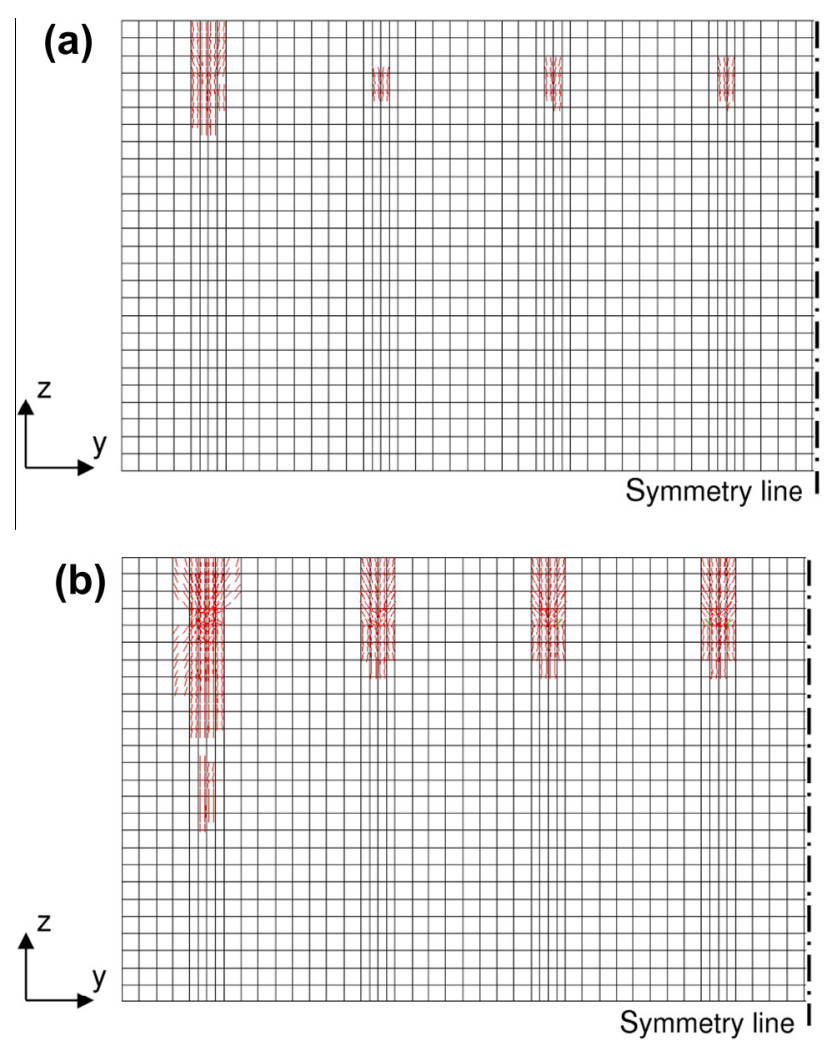

Fig. 13. Crack pattern at the internal surface of the external SFRSCC layer $\left(S_{e 1}\right)$ for the load case LC2, and for a load factor corresponding to a maximum crack width of: (a) $0.01 \mathrm{~mm}$ and (b) $0.10 \mathrm{~mm}$.

More details about the model are described by Sena-Cruz et al. [18].

\subsection{Constitutive laws and loads}

In the performed numerical simulations the fracture mode I behaviour of SFRSCC, characterised by a stress $v s$ crack width relationship $(\sigma-\omega)$, was modelled by using the following two approaches: 1 ) the tri-linear $\sigma-\omega$ diagram represented in Fig. 10a that was obtained by inverse analyses [19]; and 2) the linear $\sigma-\omega$ diagram represented in Fig. 10b that was obtained from the recommendations of fib Model Code [20], where the $f_{R, i}$ parameters were determined from the three-point beam bending tests presented in the first part of this paper [1]. In both approaches the lower bound of the experimental load vs CMOD curve was taken into account (level of confidence equal to 95\%, see Fig. 4 of the first part of this paper [1]). Also in both approaches, the measured crack width was converted into crack normal strain by dividing the crack width by the crack band width. As there is no comprehensive formulation to estimate crack width in structures that solely have fibre reinforced concrete, the adopted assumption is deemed valid.

The tri-linear softening behaviour of SFRSCC is defined by the values attributed to the stress at crack initiation, $f_{c t}$, the pair of points $\sigma_{A}, \omega_{A}$ and $\sigma_{B}, \omega_{B}$, and the fracture energy $\left(G_{f}\right)$, as shown in Fig. 10a.

The inverse analysis for obtaining the parameters that define the stress-crack width diagram represented in Fig. 10a is based on the process described elsewhere $[18,19,21]$. The procedure consists on the evaluation of the parameters that minimise the deviation between the experimental and the numerical load-CMOD curve, by brute force analysis. The error $\left(\operatorname{err}_{C M O D}\right)$ is calculated as:

$\operatorname{err}_{\mathrm{CMOD}}=\left|A_{F-\delta}^{\exp }-A_{F-\delta}^{\text {num }}\right| / A_{F-\delta}^{\exp }$ 

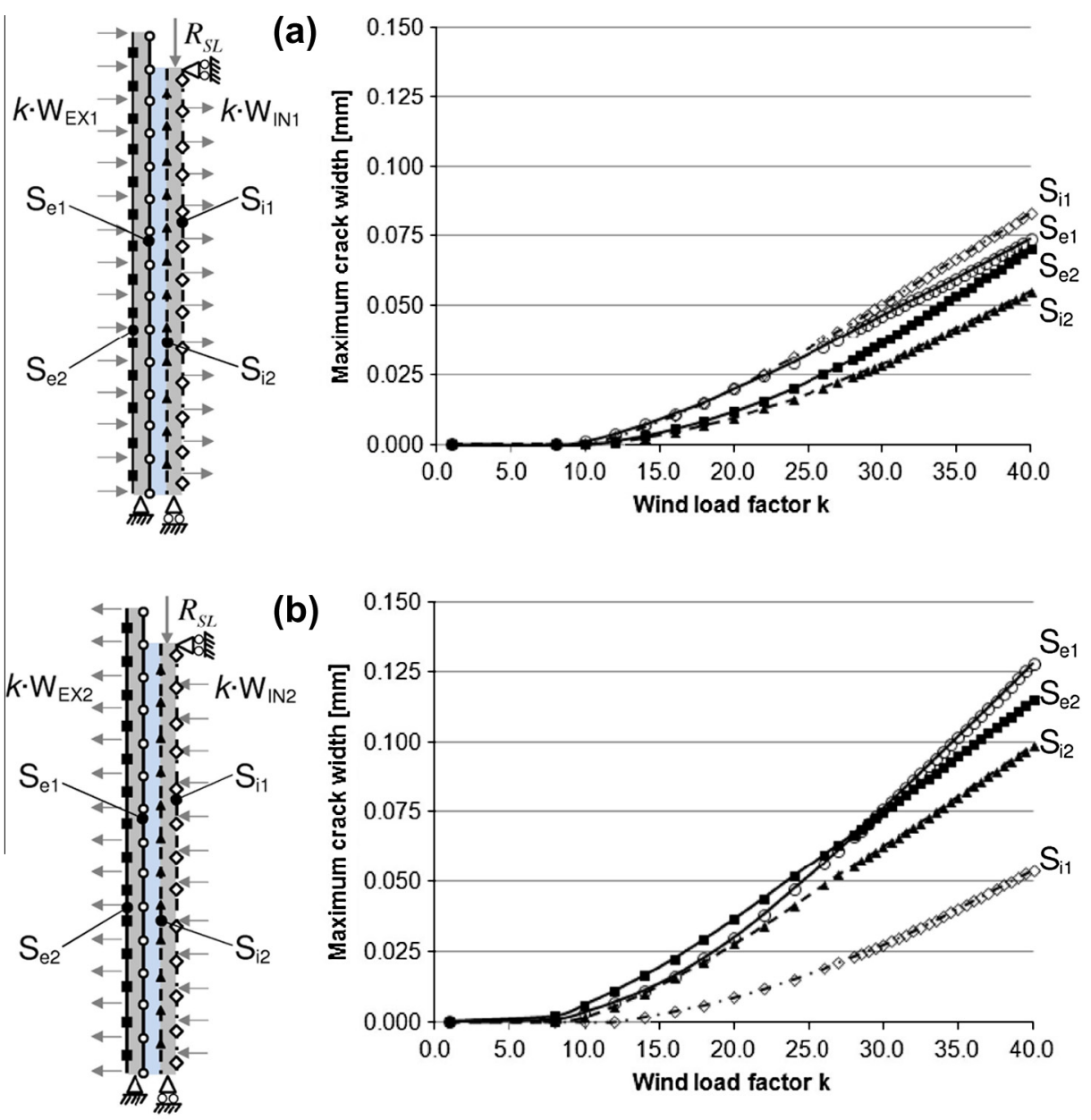

(b)
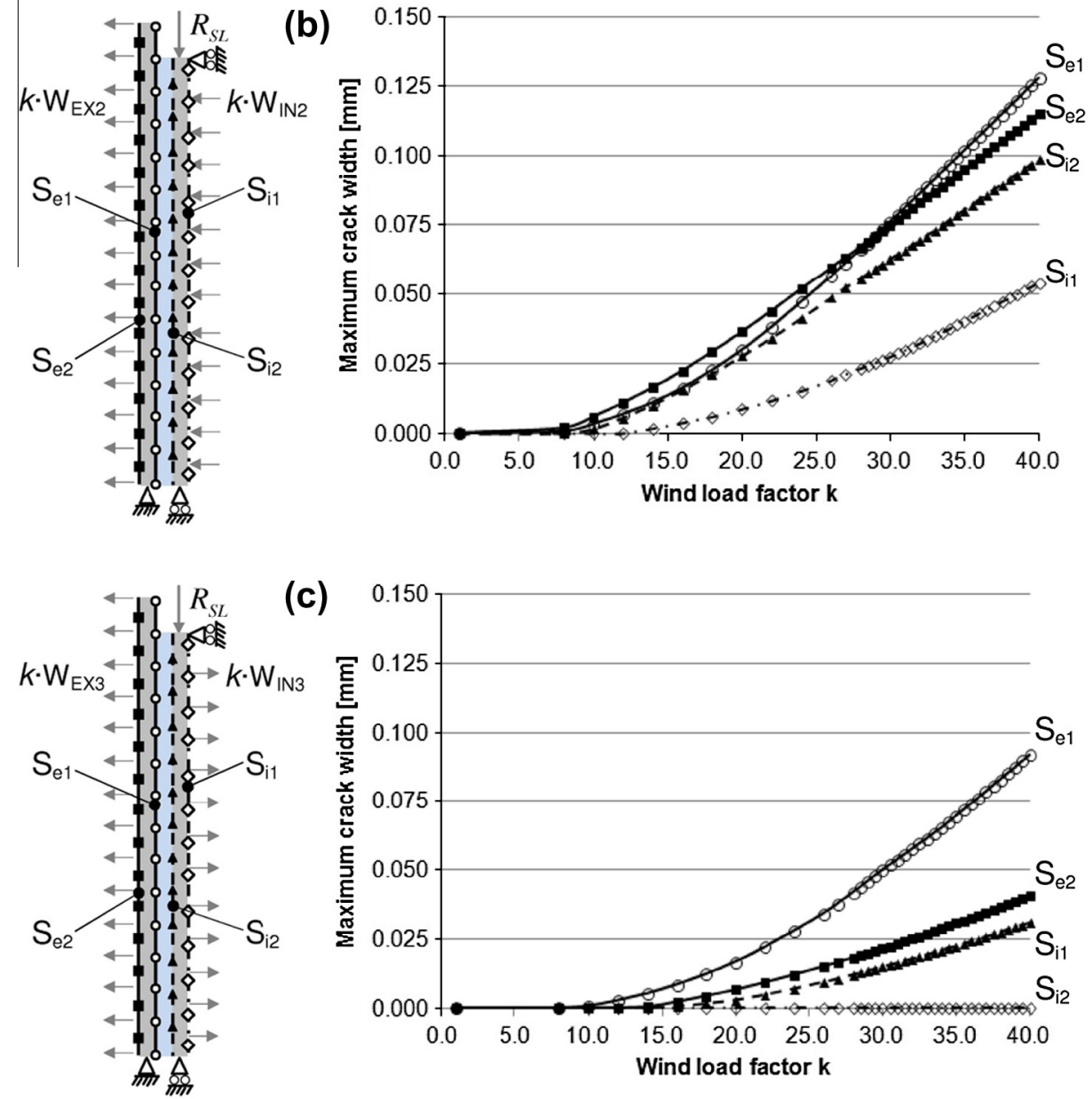

(c)

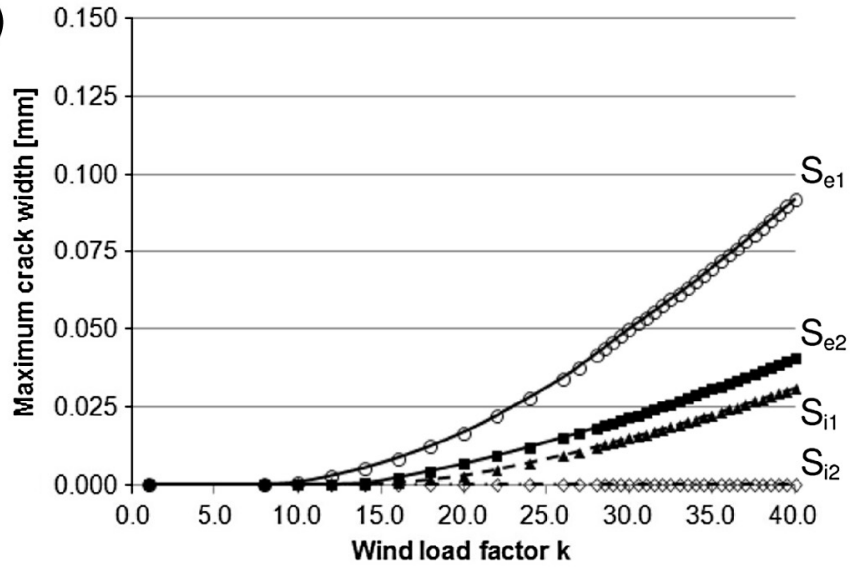

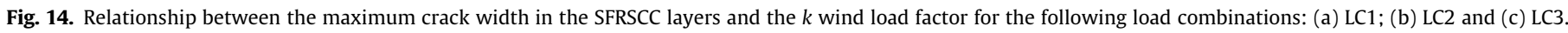

where $A_{F-\delta}^{\exp }$ and $A_{F-\delta}^{\text {num }}$ are the areas below the experimental and the numerical load-CMOD curves, respectively, up to a certain CMOD. The optimisation procedure in the inverse analysis was restricted to the interval of CMOD $0-0.5 \mathrm{~mm}$. Adopting this strategy, it is possible to obtain the stress-crack width diagram that best simulates the crack opening propagation of the developed SFRSCC up to a limit that captures the fundamental behaviour of the sandwich panel, not only for serviceability limit states, but also up to a crack opening above the maximum limits of the fib Model Code 2010.
In this paper the optimisation is done considering the experimental curve corresponding to the characteristic lower bound of the load-CMOD relationship (see [1]). The numerical curve consists of the results of a FE model to simulate the geometry of the specimens, the loading and support conditions of the three point bending tests presented in [1]. The specimen is modelled by a mesh of 8 node plane stress finite elements. The Gauss-Legendre integration scheme with $2 \times 2$ integration points is used in all elements, with the exception of the elements at the specimen symmetry axis, where only $1 \times 2$ integration points are adopted. With this 
integration point layout a vertical crack may develop along the symmetry axis of the specimen, in agreement with the experimentally observed crack initiation and propagation. Linear elastic behaviour is assumed in all the elements, with the exception of those above the notch (see Fig. 10b). For these elements, an elastic-cracked material model in tension is adopted using the discrete crack model available in the FEMIX computer program [11]. The values that defined the tri-linear $\sigma-\omega$ diagram, obtained by inverse analysis, are indicated in Table 3.

The linear $\sigma-\omega$ diagram of Fig. 10c is proposed in the fib Model Code 2010 [20], which is characterised by the parameters $f_{\text {Fts }}$ and $f_{\text {Ftu }}$. These parameters are obtained with Eqs. (2) and (3). The values considered for the flexural tensile strength parameters $f_{R, 1}$ and $f_{R, 3}$ were the lower bound characteristic values obtained from the three-point notched beam bending tests presented in the first part of this paper. The maximum crack opening accepted in structural design $\left(\omega_{a c}\right)$ was assumed equal to $0.3 \mathrm{~mm}$.

$f_{\text {Fts }}=0.45 \cdot f_{R, 1}$

$f_{\mathrm{Ftu}}=f_{\mathrm{Fts}}-\frac{\omega_{a c}}{\mathrm{CMOD}_{3}}\left(f_{\mathrm{Fts}}-0.5 f_{R, 3}+0.2_{R, 1}\right) \geqslant 0$

The $\sigma-\omega$ diagrams obtained from the two approaches are depicted in Fig. 11, where a good mutual similarity can be confirmed.

Since the linear analyses showed that the GFRP connectors always remain at stress levels well below their strength limits, they were simulated assuming a linear elastic behaviour.

For this study the same load geometry, mesh, loading and support conditions adopted in the Section 2.1 were considered. In the same way it was done in the linear elastic analyses, the perfect bond between was considered between the connectors and the SFRSCC layers. Firstly, the self-weight of the panel and the load transferred by the slab were applied, and then the wind loading was gradually applied, by multiplying the characteristic value of the wind pressure by an increasing wind load factor $k$.

\subsection{Results}

Figs. 12 and 13 represent the crack patterns for the panel under the load case LC2, respectively at the external and internal surfaces of the external SFRSCC layer $\left(\mathrm{S}_{\mathrm{e} 2}\right.$ and $\left.\mathrm{S}_{\mathrm{e} 1}\right)$.

It can be observed that a distributed pattern of fine cracks was obtained on an extensive area of the external surface of the external SFRSCC layer due to a stress field constituted predominantly by tensile stresses in the $z$ direction (external surface). In the internal surface (Fig. 13), the cracks are wider at the top extremity of the top connectors, due to the existence of the horizontal support at this region.

The relationship between the maximum crack width and the wind load factor $k$ in both SFRSCC layers is depicted in Fig. 14, where $S_{e j}$ and $S_{i j}$ represent the surfaces turned to the interior $(j=1)$ and exterior $(j=2)$ of the external $\left(S_{e}\right)$ and internal $\left(S_{i}\right)$ SFRSCC layers. These results correspond to the models with the constitutive law obtained by the inverse analysis.

The results shown in Fig. 14 indicate that the greatest crack widths are attained for the load combination LC2. Attention should be given to the fact that, depending on the wind load factor, due to the stress redistribution effects, the maximum crack width is obtained in different SFRSCC layers (internal or external) and/or in different surfaces (outer or inner surface of a specific SFRSCC layer). Specifically, in the case of the LC2, up to a wind load factor of 25.0, the maximum crack width was attained in the outer surface of the external SFRSCC layer. Above this wind load factor the maximum crack width was reached in the internal surface of the external SFRSCC layer.
Considering the most adverse load case (LC2), although the first crack opening in the SFRSCC layers appears for a wind load factor of 8.00 , a maximum crack opening of $0.10 \mathrm{~mm}$ is only attained for a wind load factor equal to 34.50 (equivalent to 23 times the wind load factor for the ULS). At this stage, the maximum compressive stress in the SFRSCC layers is $15.90 \mathrm{MPa}$ and the correspondent transverse displacement at the middle point of the internal and the external concrete layers is, respectively, $13.15 \mathrm{~mm}(\mathrm{~h} / 182)$ and $13.54 \mathrm{~mm}(\mathrm{~h} / 177)$. For this wind load factor the maximum principal tensile and principal compressive stresses in the GFRP connectors are, respectively, $184 \mathrm{MPa}$ and $169 \mathrm{MPa}$, which means that, even for transversal loads as high as 23 times the corresponding to ULS, the rupture of the GFRP connectors is not expected.

It is important to realise that the numerical model here presented is considered adequate for the evaluation of the global performance of the sandwich panel and the behaviour of the concrete wythes but has limitations regarding the behaviour of the GFRP shear connectors. The connections between GFRP and SFRSCC are modelled as perfectly bonded and it is not yet possible to model all the phenomena associated with the connectors' failure modes. In fact, if the maximum tensile principal stress in GFRP corresponding to a wind load factor $k$ equal to 34.50 (184 MPa) is compared with the maximum stress obtained in pull-out tests on the free section of GFRPs (maximum of 58.32 MPa for the TEM connector), it is concluded that the connections would have failed previously to this load factor, regardless the type of connector adopted (among the types studied in the first part of the paper [1]). Furthermore, it is necessary to keep in mind that the rupture mode of the pullout tests in [1] is clearly distinct than that which is bound to occur under flexural loadings on a long panel, thus rendering this kind of stress level comparison inconclusive. For a better understanding of the behaviour of these panels under flexure, it is necessary to perform bending tests with this sandwich system, in order to back the use of more sophisticated predictive models. Anyway, the results presented here could be representative of a panel comprising other type of connector with higher connection load capacity (e.g.: perforated plates with steel rebars passing through the holes of the connector, use of ribbed SFRSCC layers in the vicinity of the connectors, etc.).

The relationships between the maximum crack width and the wind load factor, determined by using the $\sigma-\omega$ diagrams obtained from the inverse analysis and fib Model Code approaches, are represented in Fig. 15. Since the inverse analysis conducted to a $\sigma-\omega$ diagram that has a smaller post-cracking residual strength and, consequently, smaller fracture energy, than the $\sigma-\omega$ diagram determined according to the recommendations of fib Model Code 2010, it was expected that the former approach

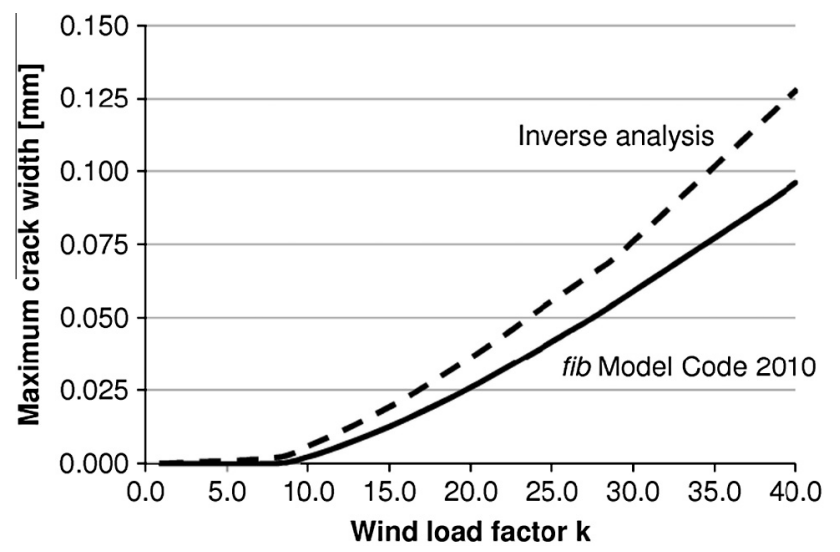

Fig. 15. Relationship between the maximum crack width and the $k$ wind load factor for the two approaches adopted to determine the $\sigma-\omega$ diagram. 
predicted larger maximum crack width for any wind load factor. As expected this discrepancy has a tendency to increase with the wind load factor. Despite the fact that using the constitutive law proposed by the fib Model Code 2010 the maximum crack width obtained is slightly lower, it seems to be an acceptable simplification, capable of predicting the behaviour of the structure with a reasonable accuracy.

\section{Conclusions}

In this study an innovative sandwich panel comprising SFRSCC layers and GFRP laminate connectors was proposed and its behaviour was investigated by numerical research. The geometry and arrangement of the panel components were optimised through a FE linear modelling. The structural behaviour of the sandwich panel was also assessed up to a relatively high damage level, by simulating the material nonlinear behaviour of SFRSCC layers due to crack initiation and propagation.

The maximum tensile stress in the SFRSCC layers was significantly affected by the arrangement of the GFRP connectors. However, for a panel configuration comprising vertical GFRP connectors spaced $1 \mathrm{~m}$ from each other, the omission of the top horizontal connector did not imply relevant changes in the principal stresses in SFRSCC and GFRP. Furthermore, the obtained results have shown that it is possible to adopt an arrangement with only discrete vertical $0.40 \mathrm{~m}$ connectors, distanced vertically $0.60 \mathrm{~m}$ and horizontally $1.00 \mathrm{~m}$ from each other, keeping the ULS stress level in the SFRSCC layers and in the GFRP connectors comfortably under the corresponding strength of these materials.

Regardless of the arrangement and thickness of the SFRSCC layers, for serviceability limit state conditions, the maximum tensile stress in the GFRP connectors was always much lower than the tensile strength of the material, which leads to conclude that, disregarding local effects in the connections, the weakest components in the panel are the SFRSCC layers. However, even for the panels composed of SFRSCC layers of $35 \mathrm{~mm}$ thickness, the maximum principal tensile stresses were lower than the characteristic tensile strength of SFRSCC. Nevertheless, as evidenced in the experimental program presented in the first part of this paper, using thicknesses of less than $60 \mathrm{~mm}$ for the SFRSCC may pose practical problems to the realisation of the embedded connection to join the GFRP connector to the SFRSCC layers.

The results obtained from the material nonlinear simulations of the sandwich panels have shown that the proposed configuration for the panel presents a ductile behaviour, even for wind load factor that is 23 times the load factor corresponding to the ULS. Ongoing experimental research with real scale prototypes is being carried out to appraise the relevant predictions provided by the FEM-based material nonlinear analysis carried out in this paper.

Despite the fact that the material nonlinear simulations of the panels, by using a constitutive law derived from the recommendations of fib Model Code 2010, have obtained slightly lower maximum crack widths, this methodology seems to be a good simplification, capable of predicting the behaviour of the sandwich panels with a reasonable accuracy.

\section{Acknowledgements}

This work is part of the research project QREN number 5387, LEGOUSE, involving the companies Mota-Engil, CiviTest, the ISISE/University of Minho and PIEP. The first author would like to thank the FCT for the financial support through the PhD Grant SFRH/BD/64415/2009. The authors also thank the collaboration of the following companies: Maccaferri and RADMIX ${ }^{\mathrm{TM}}$ for supplying the fibres, Secil and SIKA for providing the cement and the superplasticizers, respectively, and S\&P - Clever Reinforcement Ibérica for supplying the epoxy adhesive.

\section{References}

[1] Lameiras R, Barros J, Azenha M, Valente I.B. Development of sandwich panels combining fibre reinforced concrete layers and fibre reinforced polymer connectors. Part I: Conception and pull-out tests. Compos Struct 2013;105:446-59.

[2] Einea A, Salmon DC, Tadros MK, Culp TD. A new structurally and thermally efficient precast sandwich panel system. Precast/Prestressed Concr Inst 1994:39:90-101.

[3] Lucier G, Rizkalla S.H, Hassan T. Thermally efficient precast concrete sandwich load bearing wall panels reinforced with CFRP. In: 3rd fib International Congress, Washington D.C., USA; 2010. pp. (paper on CD).

[4] Pantelides CP, Surapaneni R, Reaveley LD. Structural performance of hybrid GFRP/steel concrete sandwich panels. J Compos. Constr 2008;12:570-6.

[5] Naito C, Hoemann J, Beacraft M, Bewick B. Performance and characterization of shear ties for use in insulated precast concrete sandwich wall panels. J Struct Eng 2012;138:52-61.

[6] Pessiki S, Mlynarczyk A. Experimental evaluation of the composite behavior of precast concrete sandwich wall panels. J Prescast/Prestressed Concr Inst 2003;48:54-71.

[7] Barros JAO, Pereira ENB, Santos S. Lightweight panels of steel fiber-reinforced self-compacting concrete. J Mater Civ Eng 2007;19:295-304.

[8] Benayoune A, Samad AAA, Abang Ali AA, Trikha DN. Response of pre-cast reinforced composite sandwich panels to axial loading. Constr Build Mater 2007;21:677-85

[9] Benayoune A, Samad AAA, Trikha DN, Ali AAA, Ellinna SHM. Flexural behaviour of pre-cast concrete sandwich composite panel - experimental and theoretical investigations. Constr Build Mater 2008;22:580-92.

[10] Hassan TK, Rizkalla SH. Analysis and design of precast, prestressed concrete, composite load-bearing sandwich wall panels. PCI J 2010;55:147-62.

[11] Azevedo A.F.M, Barros J.A.O, Sena-Cruz J.M, Gouveia A.V. Software in structural engineering education and design. In: III Portuguese-Mozambican Conference of Engineering; 2003. p. 81-2 [Portuguese].

[12] Peixoto S, Barros J, Sousa C, Lameiras R, Azenha M. Assessment of the structural behaviour of strips of SFRSCC-GFRP sandwich panels. 13-DEC/E-04, Civil Engineering Department. University of Minho; 2013 [Portuguese].

[13] PCI COMMITTEE ON PRECAST SANDWICH WALL Panels. State-of-the-art of precast/prestressed sandwich wall panels. Precast/Prestressed Concr Inst J 2011;56:131-75.

[14] CEN, Eurocode 1: Actions on structures - General actions - Part 1-4: Wind actions in CEN, Brussels; 2004

[15] HALFEN-DEHA, DEHA lifting anchor system: concrete, 2008.

[16] ACI Commitee 533, ACI 533R-93: Guide for precast concrete wall panels; 1993

[17] Barros JAO, Figueiras JA. Model for the analysis of steel fibre reinforced concrete slabs on grade. Comput Struct 2001;79:97-106.

[18] Sena-Cruz J.M, Barros J.A.O, Ribeiro A.F, Azevedo A.F.M, Camões A.F.F.L. Stresscrack opening relationship of enhanced performance concrete. In: 9th Portuguese Conference on Fracture. Setúbal, Portugal; 2004. p. 395-3 [Portuguese].

[19] Slowik V, Villmann B, Bretschneider N, Villmann T. Computational aspects of inverse analyses for determining softening curves of concrete. Comput Meth Appl Mech Eng 2006;195:7223-36.

[20] fédération internationale du béton, fib Model Code 2010 (final draft), 2011.

[21] Pereira ENB, Barros JAO, Camoes A. Steel fiber-reinforced self-compacting concrete: experimental research and numerical simulation. J Struct Eng 2008; $134: 1310-21$. 